\title{
$\begin{array}{lllllllll}\text { I } & \mathrm{N} & \mathrm{S} & \mathrm{T} & \mathrm{I} & \mathrm{T} & \mathrm{U} & \mathrm{T} & \mathrm{E}\end{array}$
}

\section{Rural Natives' Perceptions of Strengths and Challenges in Their Communities}

\author{
JESSICA D. ULRICH-SCHA D
}

$\mathrm{N}$ ative Americans and Alaska Natives represent a vital, and growing, constituency within rural America. ${ }^{1}$ There are 566 federally recognized tribes, as well as many others that claim descent, located throughout the United States. ${ }^{2}$ They represent a diverse array of social and cultural practices, economic circumstances, and historical backgrounds. Yet, Native ${ }^{3}$ voices are often grouped with all rural residents in portrayals of rural places. Because the challenges and opportunities Native communities and individuals face are often unique, their perceptions on key issues facing rural places deserve more exploration.

This brief uses two sources of data to explore how Natives view the current socioeconomic and environmental state of their communities and their future within them-the Community and Environment in Rural America (CERA) surveys and focus groups with Native leaders in one rural state. Overall, findings show that Natives remain firmly attached to their Native identities and culture, and that ties to the natural environment run deep.

\section{The CERA Survey and Native Respondents}

Since 2007, the CERA survey has been asking rural Americans their views on social, environmental, and economic issues pertinent to their lives and communities. ${ }^{4}$ Over 22,000 randomly selected adults from forty-three counties in fourteen states have participated in the telephone interviews (see Figure 1). ${ }^{5}$

Nearly 600 (3.1 percent) of respondents self-identified as Native (see Table 1). ${ }^{6}$ The CERA survey, however, is not representative of all Native Americans or Alaska Natives. ${ }^{7}$ The survey does not include respondents from all states, nor from each federally recognized Native tribe. Although the

\section{Key Findings}

- Among Native Americans, ties remain deep to Native identities, culture, communities, and the natural environment.

- Native Americans discussed the importance of Native stewardship of natural resources and the desire to protect those resources to help preserve their culture.

- More than one-half of Natives believe that employment opportunities, rising energy costs, poverty, affordable housing, illegal drugs, school quality, access to fresh foods, and childhood obesity are important problems in their communities. Native leaders also noted the difficulties tribes often have in meeting the basic needs of their citizens.

- Culturally based education was seen by Native leaders as an important way for tribes to pass on and build pride in their culture, and alleviate some of the persistent problems facing their communities.

- Although facing challenges, many Native Americans are optimistic about opportunities for the future.

sample is not representative, the Native CERA respondents do share certain demographic characteristics, such as education levels and incomes, with that of the U.S. Native population as a whole. ${ }^{8}$ In this brief, I examine some differences between Natives and non-Natives and among Natives by sex and region (see Table 1). 
Figure 1. U.S. COUNTIES SURVEYED by CERA

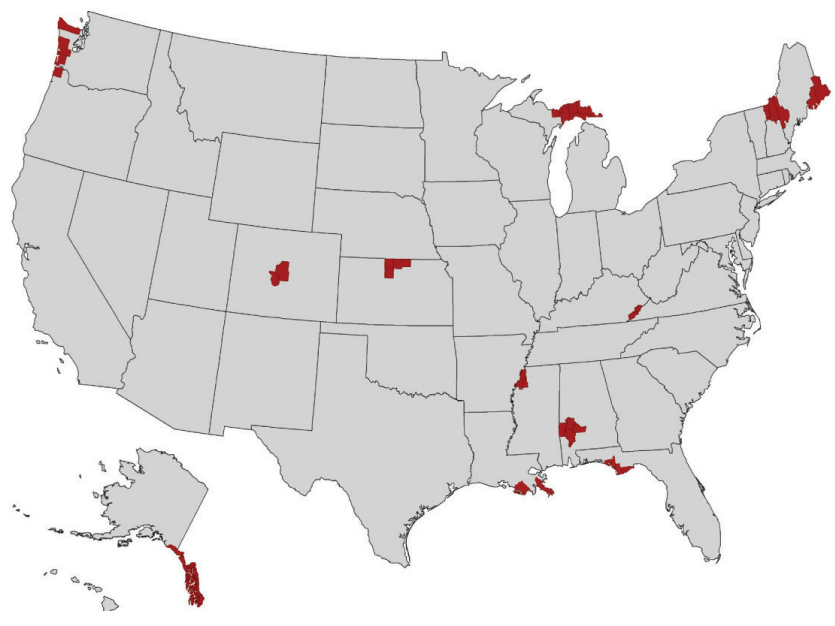

TAble 1. NATive CERA SURVey Respondents

\begin{tabular}{|c|c|c|c|}
\hline Region & $\begin{array}{l}\text { States } \\
\text { Included }\end{array}$ & $\begin{array}{c}\text { Number } \\
\text { of Native } \\
\text { Respondents }\end{array}$ & $\begin{array}{l}\text { Percent of } \\
\text { Total Native } \\
\text { Sample }\end{array}$ \\
\hline Northeast & $\begin{array}{l}\text { Maine, New Hampshire, } \\
\text { Vermont }\end{array}$ & 110 & 18.7 \\
\hline South & $\begin{array}{l}\text { Alabama, Florida, } \\
\text { Kentucky, Louisiana, } \\
\text { Mississippi }\end{array}$ & 133 & 22.6 \\
\hline Midwest & Kansas, Michigan & 87 & 14.8 \\
\hline $\begin{array}{l}\text { West (not } \\
\text { Alaska) }\end{array}$ & $\begin{array}{l}\text { Colorado, Oregon, } \\
\text { Washington }\end{array}$ & 75 & 12.8 \\
\hline $\begin{array}{l}\text { Southeast } \\
\text { Alaska }\end{array}$ & Alaska & 183 & 31.1 \\
\hline
\end{tabular}

\section{Focus Groups with Native Leaders}

In September 2010, researchers from the Carsey Institute and representatives of the National Congress of American Indians (NCAI) convened three focus groups with twentyfive Native leaders from a variety of tribes in one western state. The intent was to gather input on how social and environmental survey data might be used to support sustainable development programs, strengthen community cohesiveness, and increase the capacity of local institutions to respond to change in Native communities (see Box 1). ${ }^{10}$ The focus groups also asked participants to share their perceptions of the existing strengths and challenges in their communities. ${ }^{11}$ Each of the following sections highlight both the CERA survey and focus group findings.

\section{Native Culture Creates Deep Roots in Their Communities}

Being close to their families, in touch with their Native identity and culture, and playing an active role in their community are very important to many Natives. Among Southeast Alaska Natives-the only group large enough to be a reliable sample for this question-55 percent said that cultural or religious roles were a very important reason to stay in their community. ${ }^{12}$ This is significantly greater than the 34 percent of all non-Natives and 25 percent of Alaskan non-Natives who said the same.

Family was also integral to daily community life for the majority of Native survey respondents (see Figure 2). Sixtyeight percent said that family is a very important reason for remaining in their community, while significantly fewer (58 percent) of non-Natives said the same. ${ }^{13}$ This strong family attachment is perhaps reflective of Natives' long tenure and familial roots in their communities. Thirty-six percent of Natives have spent their entire life in their current community, and 44 percent live in the same area ${ }^{14}$ where both of their parents grew up. In comparison, significantly fewer non-Natives have lived in the same community their entire lives (31 percent) and still live in the same area their parents were raised ( 37 percent).

Like rural women generally, Native women were significantly more likely than men to see family as a very important reason to stay in their community (see Figure 2). Sixty-four percent of rural women and 53 percent of men see family as a very important reason to stay in their community. Family is an important dimension of attachment to place for most rural residents, not only Natives. Only 20 percent of all CERA survey respondents said that family is not an important reason to stay in their community.

\section{Box 1. Research in Indian Country}

Tribal leaders were uniformly skeptical of outside researchers and research in general. Prior research too frequently did not benefit (and in some cases harmed) their tribe. However, many leaders also mentioned a need for data that accurately portray the unique challenges and opportunities in Indian Country. There was a particular desire for research that tells the positive stories. Partnering with a tribal college or tribal organization, conducting face-toface research, and building tribal capacity to conduct their own research are research strategies tribal leaders saw as critical next steps. 
Figure 2. PERCENT OF RESPONDENTS WHO CITE FAMILY AS VERY IMPORTANT

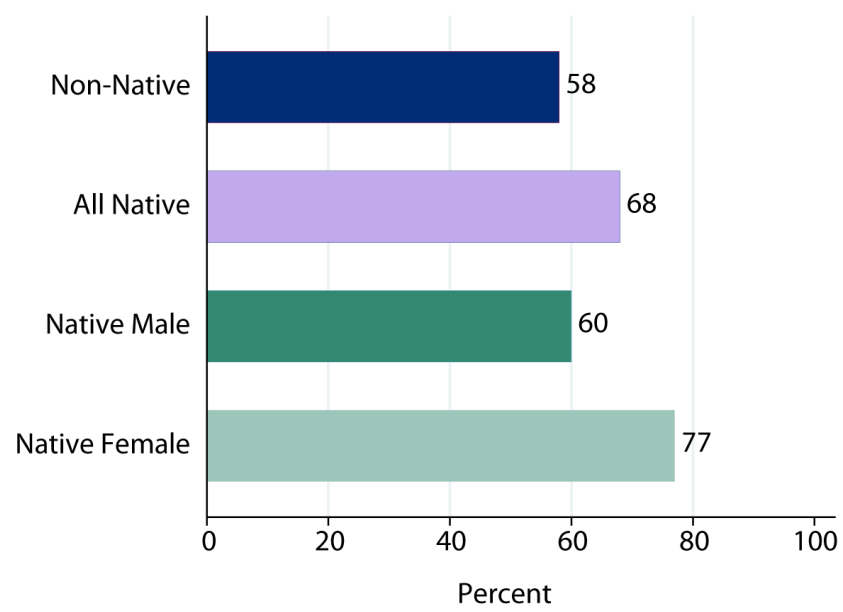

Note: In each bar graph, only variables with significant differences between Natives and non-Natives, or among Natives by region or sex, were included.

Finally, many Natives are highly involved in formal community activities and have generally positive views on community cohesion. For instance, like other rural Americans, nearly one-half of Natives said that they belong to or serve a role in a local organization that meets regularly, such as business groups, civic, service, or fraternal organizations, or local government, school, or zoning boards (see Figure 3). The overwhelming majority of all Natives also said that if faced with a local problem, community members could be counted on to work together to address the issue. They also believed that people in their community were willing to help their neighbors, and that members of their community generally trusted one another and got along. ${ }^{15}$ Natives were significantly more likely than non-Natives to believe that their community could work together to overcome a local issue, while nonNatives were significantly more likely to believe that people in their community get along and trust one another.

Focus groups with Native leaders echoed the strong, cultural, family, and community attachment revealed in the CERA survey. When asked how they would describe their community to someone who had never visited, leaders often discussed the importance of family, ceremonies, tradition, and ties to the land, as well as the strong sense of responsibility and investment within their communities. They also frequently talked about the strengths and opportunities inherent in their unique culture and value system. Many discussed their desire to protect their cultural identities by providing youth with opportunities to learn about their culture, language, history, and ancestry. Leaders believe that providing these opportunities might counter the perceived trend of youth "losing their way" in terms of their Native identity. Leaders also discussed the diversity of Indian
Figure 3. NATIVE COMMUNity INVOLVEMENT AND PERCEPTIONS OF COMMUNITY COHESION

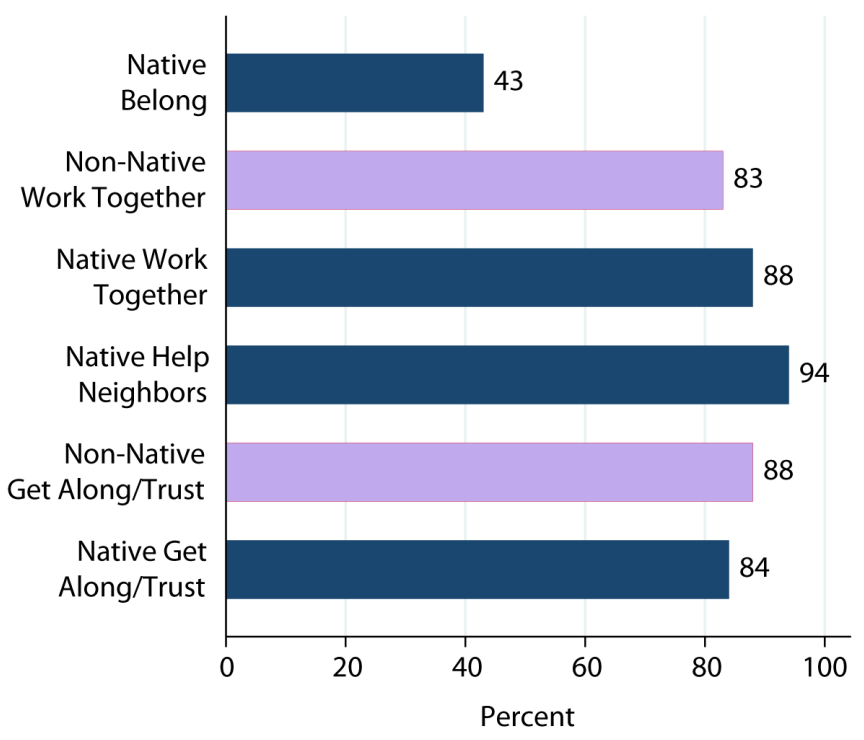

Country and their desire to educate non-Indians about their culture to prevent or disprove misconceptions about American Indians. Finally, participants discussed the complexity of tribal membership decisions. Although the survey data on this particular topic were limited, both sources of data clearly illustrate the importance of Native culture and identity in daily life that many Natives believe is important to preserve and cultivate.

\section{Natives Have Deep Attachment to the Natural Environment}

A variety of CERA survey questions illustrate the strong ties Natives have to the natural environment. As an example, two-thirds of Natives said that the natural beauty of where they live was a very important reason to remain in their community. Native men were significantly more likely than Native women to say that the natural beauty of their community was a very important reason to stay.

As further evidence of the strong ties Natives have to their natural surroundings, subsistence activities are an important means of self-sufficiency and connection to nature for many Native people. ${ }^{16}$ As was the case above, the questions on subsistence activities are limited to those from Southeast Alaska. ${ }^{17}$ The importance of these activities to Alaska Natives is evident in the fact that 73 percent reported that the ability to hunt, gather, or harvest wild fish, game, or plants was very important to them, compared with only 42 percent of all non-Natives (see Figure 4). In part, this is not surprising given the unique environmental context of Southeast Alaska. ${ }^{18}$ Alaska Natives were also significantly more likely 
Figure 4. Percent of Respondents who Cite HUNTING OR HARVESTING AS VERY IMPORTANT

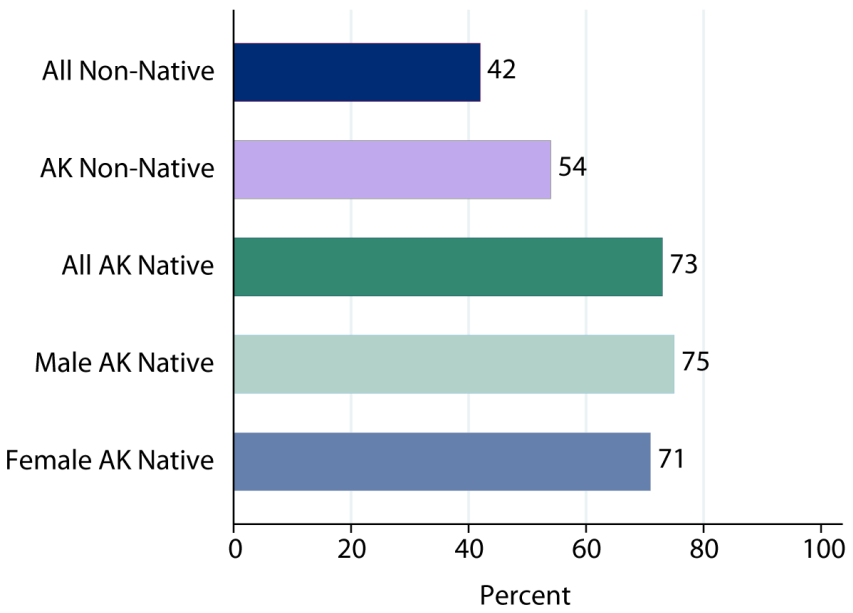

than non-Native Alaskans to say hunting or harvesting was very important. Finally, Native Alaska males were significantly more likely than females to cite local food sources as an important reason to stay.

Opinions about the stewardship of natural resources is another way to gauge attachment to the natural environment. Since 2009, the CERA survey has asked participants if they think it is more important to use natural resources to create jobs, conserve them for future generations, or both. Thirty-nine percent of Natives believe natural resources should be conserved, 33 percent said they should be used, and 28 percent said both paths would be preferable for the future of their community. Clearly there is no uniform opinion on this topic. On a related issue, significantly more Natives than non-Natives reported that conservation or environmental rules had a negative effect on their community (74 and 67 percent, respectively). Although this question is vaguely worded and does not indicate whether respondents would prefer more or less regulation, it does suggest that Natives may be frustrated with current rules surrounding the protection of natural resources and perhaps desire to have more autonomy in their stewardship.

Similar to findings from the CERA data, Native leaders in focus groups discussed the invaluable connections their tribes have to the land, the importance of stewardship of natural resources, and the desire to protect those resources to help preserve Native culture. They highlighted the difficulty in meeting these desires because of bureaucratic and inequitable regulations and limited resources. They were also concerned about non-tribal members or companies benefitting more from the extraction of natural resources than the tribes themselves. Finally, using traditional tribal knowledge for stewardship of natural resources was seen by some leaders as a way to benefit the tribes while simultaneously passing on important cultural knowledge to youth.

\section{Important Community Issues in Indian Country}

The CERA survey includes a number of questions about perceptions of local problems. More than one-half of Native respondents believed that employment opportunities, rising energy costs, poverty, affordable housing, illegal drugs, and school quality were important problems in their communities (see Figure 5). ${ }^{19}$ As in rural America overall, Natives cited a lack of employment opportunities as the most important concern (85 percent cited this as a problem). The level of concern varied significantly by region, from 94 percent in the Midwest saying jobs were an issue to 79 percent in Southeast Alaska.

Figure 5. Percent of CERA respondents Who SEe THESE ISSUES AS IMPORTANT PROBLEMS

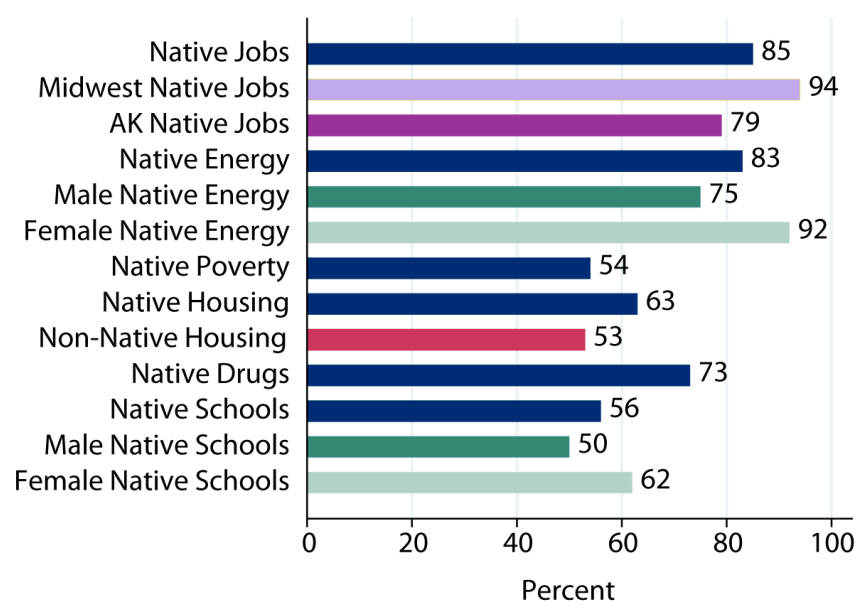

Aside from employment opportunities, rising energy costs were a pressing issue for the highest percentage of Natives ( 83 percent). The manufacturing and sale of illegal drugs, poverty, the lack of affordable housing, and school quality were also important issues for many Natives, but to a lesser extent than energy and employment. Natives were significantly more concerned about issues of affordable housing than non-Natives, and Native women were significantly more likely than men to see rising energy costs and school quality as problems.

Native leaders in the focus groups also had opinions about some of the challenges confronting their communities, including difficulties tribes often have in meeting the basic needs of their citizens. Poverty and social problems are pervasive. Many believed that dealing with the daily pressures of managing tribal institutions made it difficult to tackle larger, more systemic issues. Leaders noted that although Indian Country has many highly educated individuals who want to work in and support life on reservations, the chronically high unemployment and scarcity of employment opportunities that match their 
skills and interests inhibit them from working. Leaders also expressed a need for adequate and affordable housing, affordable energy, reliable and cheap public transportation, and a fair and effective criminal justice system. There was also concern about keeping money within the tribal communities. However, to develop the local small businesses that can serve the community and keep money local, lending practices by financial institutions must be addressed.

Education was also an important topic, particularly culturally based education, which leaders view as an important way for tribes to pass on and build pride in their culture and to alleviate some of the persistent problems facing their communities. While some leaders were optimistic about the increasing use of traditional tribal knowledge in K-12 schools, others were more critical about the quality of the schools and the education they provide. Public schools often fail Indian children, they believe, because of limited funding, low graduation rates, the scarcity of Native teachers as role models, and inadequate support for students with learning disabilities or mental health problems. On the other hand, leaders almost universally viewed tribal colleges as important educational opportunities for American Indians because of their low tuition, location within reservations, and emphasis on Native culture.

The CERA survey also asks a number of health-related questions, including about access to health services and fresh foods and childhood obesity (see Figure 6) ${ }^{20}$ Among these issues, childhood obesity was the most pressing concern to Natives, with 67 percent saying it was a very important problem in their community. About one-half said the same about a lack of health and social services and access to fresh fruits and vegetables.

Natives were significantly more likely to be concerned about the lack of fresh food access than non-Natives.

Figure 6. Percent of Respondents Who SEe these HEALTH ISSUES AS IMPORTANT PROBLEMS

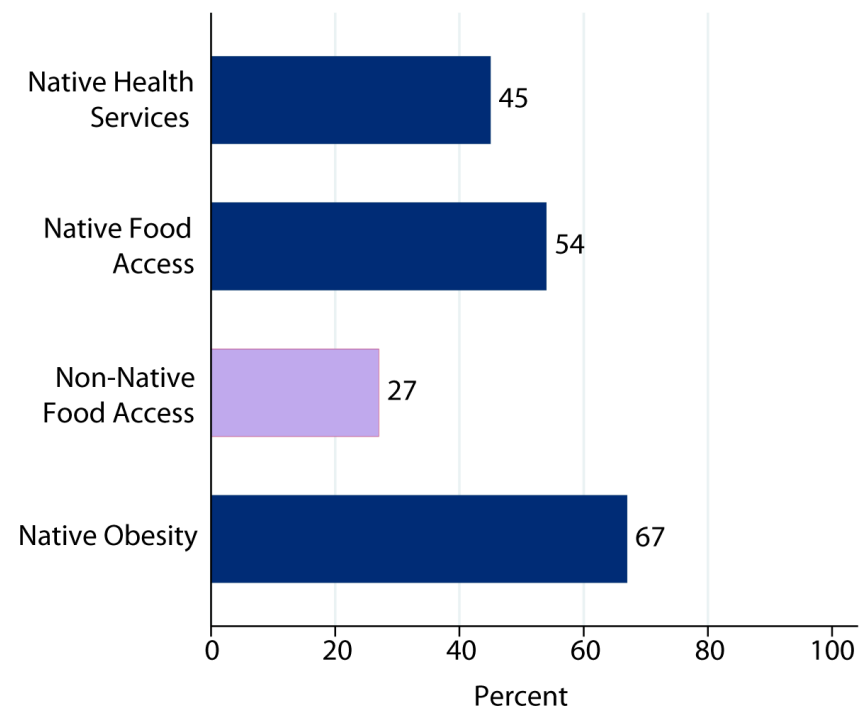

Health issues were also frequently discussed in the focus groups. Although the Indian Health Service is considered by some to be an important service received by Native people, leaders identified a number of problems. Primary concerns included the lack of preventive care and staffing resources, and the long distances to facilities. Some leaders also mentioned substance abuse (especially the recent rise of prescription drug abuse), mental health, domestic violence and neglect, obesity, and lack of access to affordable nutritious foods as problems affecting the overall health of tribal members.

\section{Native Outlooks on the Future Are Optimistic}

CERA survey data show that most Natives plan to remain in their communities and are optimistic about the future. Like the rest of rural America, a clear majority of Natives plan to stay in their communities over the next five years (79 and 84 percent, respectively; see Figure 7). Within the Native population, Alaska Natives were significantly more likely than those in the West to plan to stay. Although the high percentage of Natives who plan to stay can be seen as a positive thing for their communities, their decisions to remain may also reflect the lack of opportunities elsewhere or their inability, due to financial or other reasons, to leave.

On a final note, the CERA survey also asked respondents their perceptions of the future of their communities. Eightyfive percent believe that their community will be better off or the same in ten years. Thus, although Native communities are facing many challenges, Natives are also optimistic and hopeful about the future.

Figure 7. PERCENT OF RESPONDENTS Who PLAN TO STAY IN THEIR COMMUNITY

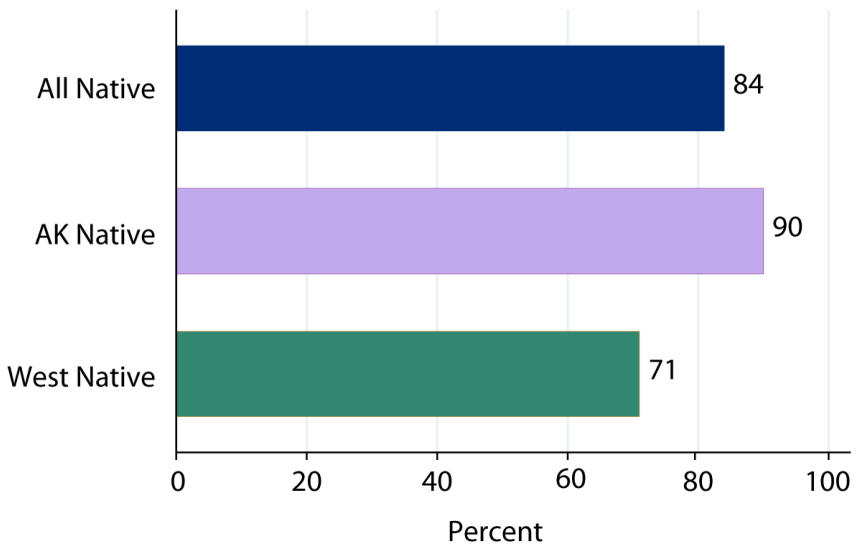




\section{Discussion}

In this brief, I use two sources of data to examine Native perceptions of the opportunities and challenges that exist in their daily lives and communities. The data help to illustrate how the Native experience is both similar to, and unique from, that of other rural Americans. Although these findings do not represent all Native tribes or individuals, they do provide a snapshot of various segments of the Native population in the rural United States. While the data illustrate that there are significant challenges facing Native people, they also show that strengths and opportunities continue to exist in Indian Country. For instance, focus group participants described well-educated tribal members, their rich culture and strong identity as American Indians, and their tribes' commitment to their communities and to stewardship of rich natural resources. In sum, I find evidence that strong intergenerational bonds that link families and communities to their shared lands, cultures, histories, and futures are prevalent.

Many rural Americans share deep connections to the natural environment and their communities, but the bonds among Native Americans and their culture and religion, family, and natural environment are often significantly stronger than their non-Native counterparts. For instance, despite the historical repression, Natives can continue to embrace their Native identity and culture. This resource (for example, cultural and social capital) could be used to help address other issues. Knowledge of and involvement in cultural practices are some of the ways Natives can enhance their sense of self and belonging, which is not only beneficial to individuals, but to the community as a whole. ${ }^{21}$ Strong attachment to their community could also discourage mobility and population loss, a growing problem in many rural places. ${ }^{22}$ On the other hand, strong cultural or religious attachment may also be an obstacle for those who want to pursue opportunities elsewhere. Natives may feel an obligation to fulfill sociocultural roles in their community, and forgo educational or employment opportunities elsewhere that might be beneficial for themselves, their families, and their communities in the long run. ${ }^{23}$

The natural environment and quality of life associated with living in their communities are clearly important to Natives. Strong ties to the natural environment for sustenance, culture, and recreation can also foster a sense of responsibility to protect the natural environment and use natural resources in a sustainable manner. By taking control of the valuable natural resources on their lands, Native nations can continue to build a stronger future for themselves while simultaneously protecting the natural environment that is so central to their culture, history, and future. In conclusion, although Native communities are short on some types of community capital (for example, financial, political, built), they have an abundance of social, cultural, human, and natural capital that could be used to combat some of the pressing issues that face their communities. ${ }^{24}$

\section{Box 2. Policies and Relations with Government}

Leaders frequently mentioned the multiple layers of bureaucracy and regulation imposed at the federal, state, and even tribal, levels, which make it difficult to accomplish meaningful change or development. ${ }^{25}$ Although they applauded the increasing representation of American Indians in politics at the state and national level, they expressed a desire to have a greater number of leaders who could serve as strong advocates for Indian Country in a wide range of settings. Rather than being seen as a "problem" or a group to assimilate into mainstream society, leaders would like their community strengths to be acknowledged, and they would like to be part of the solution for building a stronger local economy. They seek opportunities to educate non-Indians (Congressional members, in particular) about Indian Country so that "cookie cutter" policies are not applied to their diverse communities.

\section{E N D N O T E S}

1. By 2050, it is projected that American Indians and Alaska Natives, including those of more than one race, will comprise 2 percent of the total U.S. population. U.S. Census Bureau, "U.S. Population Projections, Summary Tables" (Washington, DC: U.S. Census Bureau, 2008).

2. U.S. Department of the Interior, Bureau of Indian Affairs, "Tribal Directory" (Washington, DC: Bureau of Indian Affairs, 2012).

3. Throughout this brief, the term "Native" refers to those who self-identify as American Indians or Alaska Natives.

4. For more background on the CERA survey and other publications using CERA data, see http://carseyinstitute.unh. edu/cera. CERA survey respondents are asked a core set of questions, including demographic and background information and opinions on a wide variety of socioeconomic and environmental issues important in rural places. Place-specific questions are also included in each survey to take into account important characteristics of the places surveyed. For example, CERA respondents in southeast Kentucky were asked for their opinions about the coal industry, while those in the Pacific Northwest were asked about the fishing and timber industries.

5. A National CERA (NCERA) survey was also conducted in 2011. This survey, however, was shorter and did not include many of the questions of interest for this analysis.

6. Those considered Native for this analysis include only those who identified their primary race as American Indian or Alaska Native. Respondents could also identify their race as mixed or other. Those who said they were partially Native were not included, as it is unclear whether it is their primary race/ethnicity. 
7. Native respondents were from a wide variety of places across rural America, including counties in all fourteen states surveyed in the CERA project. Almost one-third (31 percent) of Native CERA respondents were from southeast panhandle in Alaska. Many Natives in the CERA sample were also from Michigan (13 percent) and Maine (10 percent), while the remaining respondents were from nine other states representing the four major regions of the United States. The southeastern Alaskan panhandle boroughs/census areas represented in the survey are Haines Borough, Juneau City and Borough, Ketchikan-Gateway Borough, Sitka City and Borough, Yakutat City and Borough, and Prince of Wales-Hyder Census Area, Skagway-Hoonah-Angoon Census Area, and WrangellPetersburg Census Area. When referring to Alaska Natives in the brief, we are referring to these boroughs. A significant proportion of Natives live in the southwestern United States (California, Oklahoma, and Arizona, in particular); however, their voices are not represented in the CERA data.

8. CERA Natives had slightly more education and income, were older, and were more likely to be male than all Natives. For instance, in the CERA data, 13.2 percent of Natives over the age of 25 graduated from college, compared with 8.7 percent of all Natives. U.S. Census Bureau, "2010 American Community Survey for the American Indian and Alaska Native alone population" (Washington, DC: U.S. Census Bureau, 2012).

9. The name of the state is confidential in order to protect the identity of the participants as mandated by the informed consent form required by the Institutional Review Board at the University of New Hampshire.

10. Focus group participants were selected from extensive contact lists belonging to the NCAI. Because NCAI has worked on a variety of projects with Native tribes across the country and within this state, we were able to select a diverse group of potential participants from across the state to represent many tribes. We then emailed potential participants informing them of the project and asking for their participation. Attendees were compensated for their travel costs with gas cards (many drove a number of hours) and were offered meals throughout the meeting.

11. Although the focus group sessions were not audio-recorded, multiple participants took detailed notes. We systematically coded the notes and analyzed them for emergent themes. While the themes presented do not reflect the opinions of all focus group participants, they do reflect the general consensus surrounding each issue that was discussed.

12. Although we also have Native respondents from Kentucky $(\mathrm{N}=15)$, Washington $(\mathrm{N}=37)$, and Oregon $(\mathrm{N}=7)$, the samples were too small to draw any meaningful conclusions.

13. The question about the importance of family was asked in all iterations of the CERA survey except the Gulf iteration, which included residents from Florida and Louisiana. The Gulf CERA survey was modified to accommodate more direct questions about the BP Horizon oil spill in 2010.
14. This question simply asks respondents whether they live in the same "area" as their parents, which could mean different things to different people (for example, town, county, neighborhood). This may explain the discrepancy between the percentage who have lived in their current community their entire life ( 36 percent) and the percentage who live in the same area as where both of their parents grew up (44 percent).

15. See Michele Dillon and Justin Young, "Community Strength and Economic Challenge: Civic Attitudes and Community Involvement in Rural America," Issue Brief No. 29 (Durham, NH: Carsey Institute, University of New Hampshire, 2011).

16. The Harvard Project on American Indian Economic Development, The State of the Native Nations: Conditions Under U.S. Policies of Self-Determination (New York: Oxford University Press, 2008).

17. Although we also have Native respondents from Kentucky $(\mathrm{N}=15)$, Washington $(\mathrm{N}=38)$, and Oregon $(\mathrm{N}=7)$, the samples were too small to draw any meaningful conclusions.

18. See Thomas G. Safford, Megan Henly, and Jessica D. Ulrich, "Jobs, Natural Resources, and Community Resilience: A Survey of Southeast Alaskans about Social and Environmental Change," Report No. 11 (Durham, NH: Carsey Institute, University of New Hampshire, 2011).

19. This question has only been included in the CERA survey since 2009, thus it does not include Native respondents from Alabama, Colorado, Kansas, or Mississippi. It was also not included in the CERA Gulf Survey in 2010, so there are also no Native respondents from Louisiana or Florida. The CERA survey also includes questions about recreational opportunities, population decline, reliable transportation, and crime. However, these are not discussed in this brief because fewer than 50 percent of those surveyed saw them as important problems in their community.

20. The questions on fresh foods $(\mathrm{N}=239)$ and childhood obesity ( $N=236)$ have been asked only since 2010 in Southeast Alaska, Washington, Oregon, and Kentucky.

21. The Harvard Project on American Indian Economic Development, The State of the Native Nations.

22. See Kenneth M. Johnson, "Demographic Trends in Rural and Small Town America," Reports on Rural America, Vol. 1, No. 1 (Durham, NH: Carsey Institute, University of New Hampshire, 2006).

23. See Michele Dillon, "Stretching Ties: Social Capital in the Rebranding of Coos County, New Hampshire," New England Issue Brief No. 27 (Durham, NH: Carsey Institute, University of New Hampshire, 2011).

24. See Cornelia Butler Flora and Jan L. Flora, Rural Communities: Legacy and Change, 3rd ed. (Boulder, CO: Westview Press, 2008).

25. See David Treuer, Rez Life: An Indian's Journey Through Reservation Life (New York, NY: Grove Press, 2012). 
A C K N O W L E D G M E N T S

The author would like to thank Curt Grimm, Laurel Lloyd, Beth Mattingly, Bruce Mallory, Amy Sterndale, and Michelle Dillon at the Carsey Institute and Barbara Ray at Hiredpen for their comments and suggestions. The author would also like to thank Mil Duncan at AGree and Peter Morris and Emily White Hat at NCAI for their research and writing assistance.

\section{ABOUT THE AUTHOR}

Jessica D. Ulrich-Schad is a doctoral candidate in sociology at the University of New Hampshire and a research assistant at the Carsey Institute (jessicad.ulrich@gmail.com).

\section{$\triangle$ UNIVERSITY Ei. of NEW HAMPSHIRE}

\section{CARSEY}

Building knowledge for families and communities

The Carsey Institute conducts policy research on vulnerable children, youth, and families and on sustainable community development. We give policy makers and practitioners timely, independent resources to effect change in their communities.

This work was supported by the Ford Foundation and the W. K. Kellogg Foundation.

Huddleston Hall

73 Main Street

Durham, NH 03824

$(603) 862-2821$

www.carseyinstitute.unh.edu 